\title{
CIDADE, COMÉRCIO, CONSUMO E LAZER: UMA ANÁLISE A PARTIR DOS SHOPPINGS CENTERS ${ }^{1}$
}

\author{
Carlos Henrique Costa da Silva ${ }^{2}$ \\ Everton Ricardo Jampietri Leme ${ }^{3}$ \\ Joe Andrew Mateus Santos ${ }^{4}$
}

Resumo: $O$ artigo tem como principal objetivo apresentar um debate inicial e sinalizar para a contradição existente entre o lazer e o consumo nos Shopping Centers brasileiros. Breves considerações sobre a formação, expansão e consolidação do que alguns autores denominam sociedade de consumo foram feitas para apresentar a problemática. Em seguida, com base em Zygmunt Bauman, Jean Baudrillard, Henri Lefebvre e Jofre Dumazedier, discute-se os termos do lazer como necessidade para o ser humano e a sua cooptação pelos Shoppings Centers. Ao final, tomando o Shopping Center como uma forma de comércio moderna, debate-se as contradições entre o lazer e o consumo, evidenciando que na gênese destes empreendimentos o lazer aparecia como atividade secundária. Porém, com a consolidação da sociedade de consumo, estas formas do comércio conseguiram cooptar o lazer através do consumo. Atualmente, o Shopping Center é um espaço que se reproduz a partir da contradição entre lazer e consumo, revelando-se um espaço de sociabilidade que ao mesmo tempo gera e permite a exclusão social, impulsionando a segregação. Por fim, realizam-se algumas considerações a respeito da decadência dos Shoppings Centers em Sorocaba.

Palavras-chave: shopping center; lazer; consumo; comércio; Sorocaba.

\section{CITY, RETAIL, CONSUMPTION AND LEISURE: DISCUSS FROM THE SHOPPING MALLS}

\begin{abstract}
This article aims to present some initial considerations about the contradiction between leisure and consumption in Brazilian Shopping Malls from the case of Sorocaba (SP). Brief observations on the formation, expansion and consolidation of what some authors call the consumer society have been made to present the problem. Then, based on Zygmunt Bauman, Jean Baudrillard, Henri Lefebvre and Jofre Dumazedier, the discussions are terms of leisure as the need for humans and their co-optation by the Shopping Centers. At the end, taking the shopping center as a retail modern form we analysis the contradictions between leisure and consumption, showing that the genesis of these developments leisure

\footnotetext{
${ }^{1}$ Este trabalho é produto de atividades de pesquisa desenvolvidas junto ao Grupo de Pesquisas Globalização, Turismo e Sociedade de Consumo vinculado ao Laboratório de Geografia Humana, Departamento de Geografia, Turismo e Humanidades, Programa de Pós-Graduação em Geografia, CCHB/UFSCar Campus de Sorocaba. ricougo@ufscar.br.

${ }^{2}$ Professor Associado do Departamento de Geografia, Turismo e Humanidades e do Programa de Pós-Graduação em Geografia da Universidade Federal de São Carlos, Campus Sorocaba. everton.leme@gmail.com.

${ }^{3}$ Geógrafo graduado pela Universidade Federal de São Carlos, Campus Sorocaba.

${ }^{4}$ Mestrando do Programa de Pós-graduação em Geografia da Universidade Federal de São Carlos, Campus Sorocaba. joewandrew@gmail.com.

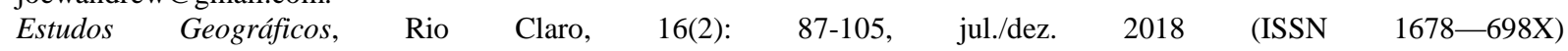

http://www.periodicos.rc.biblioteca.unesp.br/index.php/estgeo 
appeared as a secondary activity. However, with the consolidation of consumer society, these forms of retail have managed to co-opt the leisure through consumption. Currently, the Shopping Center is a space that is reproduced from the contradiction between leisure and consumption, revealing a social space that simultaneously generates and allows social exclusion, promoting segregation. Finally, perform some considerations about the decline of shopping centers in Sorocaba.

Keywords: shopping mall; leisure; consumption; retail; Sorocaba.

\section{INTRODUÇÃO}

Analisando a dinâmica da sociedade urbana contemporânea a partir do comércio, do consumo e do lazer, podemos apontar para a relação de origem entre o comércio e a cidade nos termos de Lewis Munford (1998). Desde os primórdios da história da civilização ocidental, o homem produzia seus bens para subsistência e o excedente era trocado, o que demonstra a existência das relações de troca na gênese das aglomerações humanas.

Comércio e espaço urbano possuem uma ligação genética, onde um é, ao mesmo tempo, produto e produtor do outro. Silva (2003, p. 19) aponta que "o comércio faz parte da razão de ser da cidade, viabiliza sua existência, explica sua organização e justifica inúmeros movimentos que se desenvolvem em seu interior". Vargas (2000, p.1), corrobora com essa ideia indicando que, no limite, comércio e cidade só existem com a presença do outro:

Desde o início das civilizações, comércio e cidade têm uma relação de simbiose. Ou seja, não têm significado e definham quando separadas. Ambos são causa e efeito da mesma centralidade que pressupõe o encontro do fluxo de pessoas, mercadorias, ideias e mensagens.

A urbanização moderna, como nos apresenta Sposito (2014), é guiada, sobretudo, pelo capitalismo e suas necessidades, que desde o fim do período feudal vem se transformando e expandindo, fazendo com que o espaço urbano se torne a forma material e produto mais evidente da relação entre capitalismo e urbanização. O processo de urbanização sob a égide do capitalismo se intensificou com a industrialização, conforme nos aponta Sposito (2014, p.48).

O início da industrialização entendida aqui como traço da sociedade contemporânea, como principal atividade econômica e principal forma através da qual a sociedade se apropriava da natureza e a transformava, marcou de forma profunda e revolucionou o próprio processo de urbanização. [...] Foi grande o impulso tomado pela urbanização a partir do pleno desenvolvimento da industrialização.

A partir de meados do século XIX, mas, sobretudo no século $X X$, com a industrialização crescente, o espaço urbano vai se transformar de maneira drástica e o comércio foi um dos setores que mais contribuiu para tal. Com a necessidade da produção de bens de consumo em grande escala o comércio também precisava se modernizar e ampliar sua atuação para que a engrenagem capitalista de produção e

Estudos Geográficos, Rio Claro, 16(2): 87-105, jul./dez. $2018 \quad$ (ISSN 1678 698X) http://www.periodicos.rc.biblioteca.unesp.br/index.php/estgeo 
consumo se expandisse, confirmando a integração e entre o comércio e a indústria, constituindo-se como duas faces importantes da lógica capitalista, estando sempre associadas e dependentes.

Entender esta lógica nos permite analisar que, a partir das trocas dos bens excedentes, o homem adquiriu a prática de negociar, vender, trocar, comprar e com o surgimento dos mecanismos comerciais e a produção de moedas, o fluxo de mercadorias passou a receber um significado e grande importância na sociedade. Assim, com a formação da sociedade nos princípios capitalistas no final do século XVIII, o principal objetivo capitalista, a obtenção do lucro, passou a ser a real motivação do comércio. O comércio é responsável inclusive por modificações na infraestrutura urbana para possibilitar e facilitar a circulação de pessoas, bens, riquezas e mercadorias. Pode-se afirmar que no desenvolvimento da sociedade capitalista o comércio sempre foi um elemento central para sua reprodução e hoje continua sendo uma das atividades responsáveis para dar vida e forma ao espaço urbano. Este artigo tem como principal objetivo apresentar um debate inicial e sinalizar para a contradição existente entre o lazer e o consumo nos Shopping Centers brasileiros a partir do caso de Sorocaba (SP).

Com o crescimento e as transformações nas maneiras de comercializar os produto são longo do século $X X$, as antigas formas de comércio foram desaparecendo, modificadas e redefinidas, dando lugar à novas formas, atualizadas a partir das necessidades de reprodução do capital e confirmadas pela sociedade.. Das antigas mercearias e bazares localizados na rua principal das cidades aos grandes centros comerciais regionais, novas formas comerciais foram criadas para que pudessem abrigar lojas e permitirem a realização da troca e a efetivação do consumo. "Templos da Mercadoria", conforme definição cunhada por Silvana Pintaudi (1989), como os Hipermercados e os Shoppings Centers, por exemplo, que foram criados para a ampliação do consumo. Porém, no caso dos Shoppings Centers ocorreram alterações em suas plantas originais, adaptando-as para o lazer como atrativo ao consumo. Tais mudanças nas formas comerciais ocorreram devido às mudanças e ao desenvolvimento das ideologias capitalistas que foram inseridas na sociedade, alterando valores e mudando suas estruturas, que aos poucos se tornou uma sociedade de consumo, que a cada dia torna-se mais consumista, enxergando na mercadoria a felicidade, o bem-estar.

Não obstante, a cooptação do lazer no espaço da mercadoria, foi uma ferramenta violenta de indução ao consumo. Os Shoppings Centers são espaços de segregação, locais privados de uso público e que atraem pessoas para desfrutarem das suas áreas tendo como principal objetivo induzir ao consumo, que em alguns casos ocorre desenfreadamente. O fetiche da mercadoria e o signo que ela carrega faz com que a mesma seja alvo de desejo e não mais de necessidade.

Nesta estruturação da sociedade, fundamentada no consumo, tudo está apto a tornar-se mercadoria, inclusive o lazer. Através da Sociologia do Lazer proposta por Jofre Dumazedier (1999) pode-se compreender o lazer não como ociosidade e sim como o seu contrário, ou seja, o lazer é uma forma de ocupação, uma atividade. Dentro dos Shoppings Centers o lazer torna-se uma mercadoria, mas diferente das demais, pois esta é uma mercadoria que induz ao consumo.

A contradição do lazer no espaço do consumo e a segregação causada pelos Shoppings Centers no espaço urbano são os problemas principais em discussão neste artigo, inclusive é válido apontar para os movimentos sociais que se manifestam a fim de sinalizar ao Estado e à sociedade a realização de um debate

Estudos Geográficos, $\quad$ Rio $\quad$ Claro, $\quad 16(2): \quad 87-105, \quad$ jul./dez. $2018 \quad$ (ISSN $\quad 1678$-698X) http://www.periodicos.rc.biblioteca.unesp.br/index.php/estgeo 
necessário sobre segurança e liberdade para circular e consumir no espaço dos Shoppings Centers, devido ao contínuo processo de "abandono" do espaço público, que vem ocorrendo nas cidades brasileiras. Na investigação de tal tema, além da análise bibliográfica, foram realizadas diversas observações em lócus, bem como o levantamento de dados junto a Associação Brasileira de Shopping Centers.

A relevância deste artigo centra-se no debate urgente sobre as condições de reprodução do capital pela centralidade do consumo, e para isto, trabalha-se com a tríade analítica trabalho - lazer - consumo. A partir da relação entre estes três conceitos, busca-se compreender e pontuar a contradição existente nessa tríade. Deve-se observar que quando o lazer se torna também consumo, há efetivamente a sinalização da precarização e da alienação do trabalho na sociedade contemporânea, onde numerosos trabalhadores estão privados de empregos dignos devido ao subdesenvolvimento tecnológico ou tantos outros motivos, condenando alguns a empregos esporádicos de curta duração. Quando estes trabalhadores vão ao Shopping Center, em sua maioria, realizam atividades que consideram ser lazer, mas que na verdade o que praticam é um lazer controlado pela lógica capitalista e reproduzível a partir do fetiche da mercadoria, evidenciando-se a cooptação do lazer no interior desta forma comercial. É importante reiterar que não se quer aqui profligar o espaço do consumo, mas criticar a cooptação violenta do lazer neste ambiente.

\section{A SOCIEDADE DE CONSUMO}

Entender o comércio e o consumo na atualidade tem sido um fator fundamental para compreender também as dinâmicas socioespaciais. A análise do comércio, desde o seu surgimento, nos permite notar um grande desenvolvimento das possibilidades de troca e intercâmbio de mercadorias, ressaltando que estas possibilidades se inscrevem, antes de qualquer coisa, como relações sociais. Através da estabilização econômica da burguesia, esta classe social necessitava de uma modificação em seus modos de vida através da produção de relações que fossem prioritariamente relações de produção de capital. Concorda-se com Granou (1975, p. 48) quando ele afirma que:

O capitalismo não podia impor-se definitivamente contra os modos de produção anteriores se não levasse a revolução começada na 'maneira de produzir' até à maneira de produzir e até ao modo de reprodução da vida. Dissolver o antigo modo de vida e reconstituí-lo na base das revoluções capitalistas, impor aquilo a que se chamará 'o reino da mercadoria', tal é em definitivo a condição do alargamento a toda a sociedade das relações de produção capitalistas, a condição para um novo lançamento (provisoriamente) durável da acumulação do capital.

Com isso surge uma nova dimensão da sociedade a partir da profusão dos bens de consumo. A alteração nos modos de vida, no modo de produção, a expansão da indústria, dos transportes e dos meios de comunicação permitiram que essa sociedade se solidificasse, tornando-se padrão dominante. Conforme Silva (2009, p.66):

Estudos Geográficos, $\quad$ Rio $\quad$ Claro, $\quad 16(2): \quad 87-105, \quad$ jul./dez. $2018 \quad$ (ISSN 1678 -698X) http://www.periodicos.rc.biblioteca.unesp.br/index.php/estgeo 
A emergência dessa sociedade de consumo, é fruto dos avanços e das mudanças que a sociedade, principalmente neste século, sofreu. Os processos de mudança produtiva e de difusão das mercadorias possibilitaram que novos valores sociais fossem surgindo, fundamentalmente baseados no consumo.

Marx (1859, p.246) em sua crítica da economia política define claramente que "a produção é imediatamente consumo", aquilo que os economistas chamam de consumo produtivo, onde a produção corresponde diretamente ao consumo e o consumo coincide imediatamente com a produção. Uma relação intrínseca, pois para que haja produção é necessário o consumo e para que exista o consumo é necessária à produção. Segundo Marx (1859, p.246):

Portanto, a produção é imediatamente consumo, e o consumo é imediatamente produção; cada termo é imediatamente o seu contrário. Mas, simultaneamente, há um movimento mediador entre ambos; a produção é intermediária do consumo, cuja matéria cria; sem esta, aquele ficaria privado do seu objeto; por sua vez, o consumo é intermediário da produção, pois proporciona aos seus produtos o sujeito para o qual eles o são (produtos). O produto só atinge o seu finish final no consumo. Uma via férrea onde não circulam trens, que não é usada, que não é consumida, pode dizerse que é imaginária, que não existe. Sem produção não há consumo; mas sem consumo, também não há produção, pois, nesse caso, a produção seria inútil.

O consumo aparece como um integrante indissociável da produção, pois o consumo dos objetos irá conduzir a produção destes produtos destinados a diversos grupos. Porém, para entendermos melhor a lógica do consumo é preciso compreender que o consumo das massas não é movido pela necessidade e sim pelo desejo. Braudrillard (1996) ao afirmar que o consumo invadiu toda a vida e que o mesmo é governado por um pensamento mágico, trata-o a partir da onipotência dos signos. Quando consumimos, não levamos apenas um produto, mas o signo que ele carrega. Nesta direção, Henri Lefèbvre (2001, p.64) afirma que:

A produção desses signos se integra na produção global e desempenha um papel integrador fundamental em relação às outras atividades sociais e produtivas ou organizadoras. O signo é comprado e vendido. Sob a aparência de signos e significação em geral, são significações desta sociedade que são entregues ao consumo.

Com isso, é inevitável falar sobre o papel da mercadoria dentro da sociedade de consumo. Entendemos que na sociedade de consumo, o indivíduo é "programado" dentro do sistema capitalista a trabalhar incessantemente, alguns exaurindo suas forças físicas e mentais, para a aquisição de algo material (ou não) para que no ato da compra o consumidor, que teve seu tempo de trabalho convertido em dinheiro, possa agora converter seu dinheiro em um produto de desejo, produto este que possa dar-lhe algum prazer, e não somente isto, o próprio ato de simplesmente consumir é na sociedade de consumo algo com um grande significado. É através do consumo que o indivíduo pode materializar, por meio da

Estudos Geográficos, $\quad$ Rio $\quad$ Claro, $\quad 16(2): \quad 87-105, \quad$ jul./dez. $2018 \quad$ (ISSN 1678 -698X) http://www.periodicos.rc.biblioteca.unesp.br/index.php/estgeo 
mercadoria, a imagem que ele deseja efetivamente mostrar dentro da sua classe social e da sociedade de modo geral.

Bauman (2008) aponta que a concretização da sociedade de consumo se dá no momento em que a mercadoria assume papel central na sociedade, sendo a mediadora inclusive das relações sociais. O consumo passa a ser então o ponto central de estruturação da sociedade quando todas as necessidades (criadas ou reais) se resolvem através do consumo. Baudrillard (1991, p.47), afirma que as necessidades criadas e recriadas pelo capital e reproduzidas na vida cotidiana surgem como caminho imperativo para a reprodução social que, através do consumo, busca suprir as imprescindíveis exigências feitas por essa estruturação:

Todo o discurso sobre as necessidades assenta numa antropologia ingénua: a da propensão natural para a felicidade. Inscrita em caracteres de fogo por detrás da menor publicidade para as Canárias ou para os sais de banho, a felicidade constitui a referência absoluta da sociedade de consumo, revelando-se como o equivalente autêntico da salvação.

Neste sentido, a relação do indivíduo com a mercadoria deixa de estar na esfera das necessidades e no plano econômico, mas passa a ser uma relação de significados, uma imagem ou um status dentro de um grupo. Neste âmbito, pode-se afirmar que o indivíduo não compra apenas um objeto, mas o símbolo que ele carrega. A mercadoria é a materialização do ser do indivíduo. Conforme Silva (2014, p. 31).

\begin{abstract}
Vale ressaltar que atualmente, a necessidade natural, como a de comer ou a de se vestir, não é mais satisfeita pelo simples fato de comer um alimento, beber um líquido ou de vestir uma roupa ou sapato. A satisfação dessas necessidades, por exemplo, dentro de nossa sociedade capitalista, é mediada por uma série de objetos e representações sociais. Faz tempo deixaram de ser meras necessidades naturais para se tornarem necessidades sociais. Deste modo, as necessidades são criadas e satisfeitas por meio de coisas, mediadas pelo mercado.
\end{abstract}

A partir deste pensamento, foram criadas nas cidades novas formas de comércio para que o consumo pudesse ser concretizado e essas relações pudessem ser realizadas. Conforme Lefebvre (1991, p.46), "Ela muda quando muda a sociedade em seu conjunto" e com a mudança do padrão econômico, de produção e consumo, a cidade foi se tornando evidentemente uma condição e um produto da reprodução social. Os novos estabelecimentos comerciais vieram concentrar atividades onde os consumidores não consumiam somente mercadorias, mas como afirmou Lefebvre (1991, p. 67) o consumidor, também vem consumir o espaço "(...) razão e pretexto para reunião de pessoas, elas vêm, olham, falam, falam-se. E o lugar de encontro, a partir do aglomerado das coisas". Segundo Padovani (2003, p. 172):

A cidade é o lugar privilegiado para a reprodução das relações de produção em seu âmbito político, econômico e social; ela é produto, condição e meio para que esse processo aconteça. Ela divide, mas ao mesmo tempo une os lugares, que se entrelaçam no contexto da

Estudos Geográficos, Rio $\quad$ Claro, $\quad$ 16(2): $\quad 87-105, \quad$ jul./dez. $2018 \quad$ (ISSN 1678 -698X) http://www.periodicos.rc.biblioteca.unesp.br/index.php/estgeo 
produção e reprodução. A cidade, fruto do trabalho humano, é criação, é produto social e, portanto, historicamente produzida. Assim como outras mercadorias, é comercializada e apropriada de maneira particular, produzindo segregação. As relações existentes nas cidades, sem dúvida são as grandes responsáveis pelo modo de vida urbano, e os processos que nela acontecem extrapolam seus limites, pois interferem de forma integral em todos os espaços.

Pintaudi (2008, p.123), aponta que:

Com a incorporação de novos objetos técnicos, que deram maior fluidez ao espaço, fragmenta-se o espaço urbano, particularmente nas grandes cidades, que se tornam polinucleadas, desiguais, com emergência de diferentes centralidades para atender a distintos segmentos sociais. Se num deles acompanhava novas áreas ocupadas, isso não se verifica na atualidade: hipermercados e shopping centers são capazes de criar a própria centralidade e se antecedem à própria cidade, ou ainda, se antecipam à cidade, ou melhor, ao aglomerado. [...] esses espaços são determinantes na criação do entorno e lhe conferem o sentido.

Neste sentido, entendemos que é na cidade que as segregações serão concretizadas. Se em um primeiro momento Padovani (2003) afirma que a cidade é comercializada assim como outras mercadorias, produzindo segregação, Silvana Pintaudi (2008) afirma que os novos espaços como hipermercados e shopping centers criam suas próprias centralidades, moldando a malha urbana. É com isso que compreendemos que, no momento que a cidade se torna mercadoria e os espaços do consumo criam suas centralidades, tais espaços tornam-se signos para toda sociedade, ou grande parte dela, porém são destinados a determinados grupos de pessoas e não para toda sociedade. Os espaços de consumo passam a ter uma importante função na formação do espaço urbano através da centralidade que estes locais congregam. A partir disto estes espaços passam a ser também consumidos. Há então, como Pintaudi (2008) afirma um consumo do espaço de consumo. O consumo passa a ser a razão para reunir pessoas nesses lugares, tornando-se motivador para o contato entre as pessoas. Tornam-se "templos da mercadoria" (Pintaudi, 1989), aonde ocorrerá a última metamorfose da mercadoria, ou seja, a transformação de dinheiro em mercadoria. Como disse Marx (1973, p.157) "se, por um lado, o dinheiro representa mercadorias vendidas, por outro lado representa também mercadorias a comprar". Conforme Silva (2009):

Por esta compreensão, as formas comerciais, sobretudos as modernas Shopping Center, Hipermercados, Lojas de Departamento, Supermercados, Sistemas de Franquias, etc.- podem ser assim considerados os templos da mercadoria, onde ela se torna o sujeito principal de toda a vida, é o lugar primaz da reprodução da mercadoria, do seu ideal.

O fetichismo da mercadoria é o objetivo dos templos de consumo. A mercadoria tornou-se o fetiche dessa sociedade, o modo como os grandes centros de consumo se organizam, as vitrines, as propagandas (marca importante do capitalismo), o avanço da tecnologia possibilitaram uma avultada divulgação de informações para os consumidores, acelerando a exposição dos produtos, que, por $\begin{array}{lllllll}\text { Estudos Geográficos, } & \text { Rio } \quad \text { Claro, } & 16(2): & 87-105, & \text { jul./dez. } & 2018 \quad \text { (ISSN } & 1678-698 X)\end{array}$ http://www.periodicos.rc.biblioteca.unesp.br/index.php/estgeo 
meio da mídia, criam neles o desejo de obtê-los, muitas vezes sem existir uma real necessidade. Isso impulsiona o indivíduo a querer consumir aceleradamente, para estar de acordo com os padrões impostos pela sociedade, e saciar alguns impulsos inconscientes.

\section{SHOPPINGS CENTERS: LAZER, COMÉRCIO E CONSUMO}

Procurou-se até aqui analisar o surgimento e o desenvolvimento da sociedade de consumo e observar como o consumo tomou uma posição de evidência na vida da sociedade contemporânea. Consumo não somente de mercadorias produzidas em linhas de produção, mas também o consumo do espaço. A análise agora se centra nos Shopping Centers a partir de dois conceitos importantes que se efetivam neste local: o lazer e o comércio. Antes de tudo é importante destacar que o Shopping Center, para seus proprietários, não é um espaço produzido, concebido e nem percebido para a realização do lazer, mas que tem neste uma importante ferramenta para a indução ao consumo.

O conceito de lazer é amplamente discutido no âmbito das ciências humanas e sociais, pois representa uma importante expressão das transformações socioculturais vividas na contemporaneidade. É importante matizar que, dada a pluralidade de sentidos e definições usadas pelos autores para caracterizar estas transformações contemporâneas, não se trata de aprofundá-las, senão tentar refletir sobre a influência destas transformações do uso do lazer e suas manifestações. Em 1883, Paul Lafargue, contemporâneo e genro de Karl Marx, escreveu o primeiro panfleto a favor do lazer dos operários na Europa iniciando com o questionamento "O trabalho é um fim ou um meio?". Esta pergunta se apresenta como urgente para o debate, ao se entender que nas sociedades pré-industriais, as atividades lúdicas, hoje atribuídas ao lazer, estavam ligadas ao culto, à tradição, às festas e não existia de fato o lazer em si, pois as atividades de trabalho envolviam ludicidade e prazer criativo.

Dumazedier (1999, p. 248), um dos sociólogos que mais se dedicou a estudar o lazer, afirma que há inúmeras formas para entendê-lo, porém reafirma sempre a importância do mesmo desde o início de sua obra.

Semanas de 40 horas, aposentadoria aos 60 anos, evasão escolar, trabalho doméstico contestado...: o que fazer com o tempo livre? 0 lazer é uma de nossas grandes obcessões e, no entanto, permanece mal conhecido: suas dimensões reais estão escondidas na representação dominante, estereotipada e mítica de suas relações com o "trabalho" e outros compromissos sociais.

Por este autor, pode-se pensar na necessidade humana que o lazer é, e que pode ser inclusive bem aproveitada para o momento do trabalho no sentido de que, ao analisar que o lazer é algo escasso, quando ele é usado, o indivíduo aumenta sua qualidade e a sua produtividade em termos de elevação do espírito e produção de ideias que pode ser revertida dentro do seu local de trabalho. O termo lazer pode ser associado a palavras como entretenimento, turismo, divertimento, recreação, mas o seu sentido é amplamente discutido assim como a origem do conceito de ócio. Dumazedier (1999, p 123-127) classifica os diferentes tipos de lazer em:

Estudos Geográficos, $\quad$ Rio $\quad$ Claro, $\quad 16(2): \quad 87-105, \quad$ jul./dez. $2018 \quad$ (ISSN $\quad 1678$-698X) http://www.periodicos.rc.biblioteca.unesp.br/index.php/estgeo 
a) Lazeres Físicos: prática de esportes e atividades físicas (menos praticas na terceira idade)

b) Lazeres Artísticos: visitação de museus, monumentos, paisagens de diversas regiões.

c) Lazeres Práticos: dentro de casa, atividades manuais, jardinagem.

d) Lazeres Intelectuais: Principalmente a leitura de livros, jornais etc.

e) Lazeres Sociais: Recepções, visitas feitas e recebidas.

Neste sentido observa-se a ausência de lazeres relacionados ao consumo, que como sabemos é a forma como a sociedade se organizou, vivendo para o consumo e pelo consumo.

A facilidade de acesso aos bens de consumo aumentou com a industrialização e a urbanização extensiva, processo que se intensificou no Brasil a partir da década de 1950 e que proporcionou um significativo avanço em diversos setores. Além disso, os sistemas de infraestrutura facilitaram a circulação e distribuição dos bens produzidos. A indústria foi gradativamente sendo capaz de produzir bens materiais em maior escala e em menor tempo. Neste sentido, o comércio foi ganhando cada vez maior importância na geração de lucro para a realização do consumo. A partir de Chiavenato (1999, p 43.) pode-se refletir sobre este processo:

A facilidade de acesso aos bens de consumo aumentou com a industrialização. Esse facilitário vem ocorrendo no Brasil desde 1930 quando a indústria começou a se expandir a os salários subiram. A legislação trabalhista não ofereceu só vantagens salariais, mas garantiu direitos inéditos aos operários brasileiros.

Não obstante, o comércio avançou paralelo a este processo idealizando seu objetivo capitalista, o lucro. Invoca-se aqui a lembrança da afirmação de Karl Marx sobre a relação imediata entre produção e consumo. Ao se analisar o comércio entende-se que este é uma etapa da tríade produção, circulação e consumo. Assim, o comércio corresponde a importante atividade da distribuição das mercadorias em que se estabelece a troca dos bens de consumo. O comércio é a ponte que interliga a mercadoria ao consumidor. Segundo Barata Salgueiro (1995) depois da Segunda Guerra Mundial ocorreram importantes modificações no padrão geográfico dos estabelecimentos comerciais, em paralelo com alterações na dimensão, nível de especialização e agrupamento das unidades. Assim, para atender a população e a intenção de ligar a mercadoria ao consumidor, novas formas de comércio foram criadas, agrupando em um mesmo local itens diversos.

O Shopping Center atualmente se caracteriza como um simulacro da cidade, pois é um espaço que reúne diferentes formas de comércio como lojas de diversos setores, sobretudo vinculadas ao sistema de franquias, praças de alimentação, pátio de estacionamento, quiosques, serviços diversos etc., com a intenção de proporcionar aos frequentadores conforto e segurança. Um local alijado da violência e dos problemas cotidianos. Neste sentido, observa-se que na constituição desses empreendimentos, o lazer é uma mercadoria fundamental, pois é uma mercadoria que leva ao consumo das demais presentes naquele espaço. Os diversos espaços dentro do Shopping Center como as salas de cinema, os restaurantes ou mesmo as prateleiras que ficam dispostas no caminho dos caixas para o pagamento, são uma Estudos Geográficos, Rio Claro, 16(2): 87-105, jul./dez. 2018 (ISSN 1678-698X) http://www.periodicos.rc.biblioteca.unesp.br/index.php/estgeo 
atração fortíssima ao consumo, e isto fica muito claro quando se frequenta o Shopping Center com crianças. Logo quando elas se deparam com as "atrações" infantis temporárias ou mesmo quando se frequenta o cinema e se induz a compra de um item da prateleira, pois o ato de não comprar ou não brincar pode fazer da ida ao Shopping menos divertida e até mesmo incompleta. Como explicitado por Granou (1975, p.52) quando discorre sobre o reino da mercadoria, este autor analisa as relações mediadas pela mercadoria e cita que "a produção de lazeres não tem como objetivo uma produção de valores, ela é apenas o suporte de uma produção de valor de troca, de mais-valia". Através do trabalho de Silvana Pintaudi (2008) pode-se refletir a respeito da solidez e da forma como este espaço da mercadoria irá se apresentar para a sociedade, quando analisa que nos últimos anos novas tecnologias foram implementadas nestes empreendimentos. Observa-se que eles tornaram-se também um signo, consumir nestes espaços é também carregá-los como signo. Porém, a autora (2008, p.124) faz um alerta ao afirmar que "uma forma comercial, para durar tem de ter capacidade de resistência, precisa ter um sentido, criar raízes, mas para isso ela tem de ser atualizada para dialogar com as formas emergentes". Pintaudi ainda afirma que (2008, p. 126):

O espaço, como mercadoria, também vai ser consumido enquanto signo. Hoje, o lugar da compra, tal como a mercadoria a ser comprada, deve ser diferenciado, deve ter uma marca de distinção de outros que contém mercadorias que não seriam distinguidas e valorizadas se assim não fosse. O lugar como signo se torna abstrato, é consumido como tal, um espaço de consumo que se repete pelas formas que já emergiram. [...] o que é arcaico pode ser diferente num primeiro momento, mas na repetição torna-se indistinto. O fato é que o espaço precisa ser considerado também na perspectiva de consumo do espaço - uma mercadoria que envolve outra, valorizando-a e conferindo distinção àqueles que 0 frequentam.

É importante analisar de maneira fragmentada esta citação. A autora afirma que o Shopping Center é em sua multiplicidade um local de atração de pessoas, sendo ele o espaço da mercadoria que também é consumido como signo. Porém, ele deve ter uma marca de distinção dos demais de sua mesma natureza. Destacase aqui aqueles grandes complexos como o Iguatemi Esplanada de Sorocaba, ou outros Shoppings Centers de envergadura regional com alto fluxo de consumidores e grande circulação de dinheiro. Assim, é interessante destacar que na sociedade de consumo atual há diferenças marcantes para o consumidor quando este compra em um ambiente frequentado e construído para indivíduos com rendimentos altos e quando o consumo é realizado em um Shopping Center popular com alta circulação de pessoas com baixo poder aquisitivo. É neste contexto que estes grandes complexos de compras vão criando entre si e para o mercado consumidor distinções, que podem ser vislumbradas pela infraestrutura dos estabelecimentos, tipos de lojas, localização e consumidores.

\section{O LAZER COOPTADO PELO CONSUMO}

Neste momento, analisa-se o lazer de modo a entendê-lo como ferramenta de indução ao consumo, tomando um espaço que por sua vez não é seu e, por

Estudos Geográficos, Rio Claro, 16(2): 87-105, jul./dez. $2018 \quad$ (ISSN 1678 -698X) http://www.periodicos.rc.biblioteca.unesp.br/index.php/estgeo 
conseguinte, tornando o espaço dos Shoppings Centers um espaço de sociabilidade, mas gerando contradições e exclusões dentro da sociedade, mostrando que o Shopping Center não é e nunca foi um espaço para ser tomado como um local de passeio simplesmente.

O que se propõe como reflexão é compreender como o Shopping Center se torna um local de encontros, onde há a sociabilização. Impulsionada pela diversidade social e cultural dos sujeitos que estão presentes neste espaço é notória a distinção das classes sociais, tornando-se então uma das maiores fontes de discriminações nesses centros de consumo. Alguns desses locais chegam a restringir o acesso de certos grupos ou até mesmo limitar a quantidade de pessoas que circulam juntas pelos corredores. Ao estabelecer limites e restringir o acesso a apenas uma parte da população, os Shopping Centers acabam gerando um problema social. Em muitos casos há uma velada seleção daqueles que podem ou não visitar o Shopping Center. Na maioria dos casos, observa-se funcionários com olhar moldado pelo preconceito, analisando a indumentária dos indivíduos e utilizando estas como objetos de identificação e permissão. As vestimentas também são fonte para os diferentes tipos de abordagem que os vendedores darão aos clientes, pois se acharem que o comprador não está de acordo com os padrões convencionados para o local, rapidamente encontrarão um meio de dispensá-lo, tornando a relação de consumo um momento ímpar, de destaque, da sociedade do parecer.

O sistema capitalista por si só é contraditório, as relações sociais são contraditórias, os movimentos sociais são contraditórios, a contradição está presente em nossos meios e fins. Segundo Kohan $(2005$, p.3) "A crise do capitalismo constitui a exposição de múltiplas contradições antagônicas. A mudança e o movimento da história são produtos dessas contradições". Assim, analisando os Shoppings Centers, vê-se que estes espaços são contraditórios, pois são um simulacro das cidades e que segundo Wypych (2010, p 141) "é um local onde não se pode encontrar a pobreza nem a deterioração, que normalmente se encontra na cidade", simulando um espaço perfeito e confortável para comprar. Porém é confirmado por Pintaudi (2005, p. 153) que "os shopping centers foram construídos para atender a uma população de altos rendimentos, que na década de 80 se traduzia em $20 \%$ da população economicamente ativa", o que nos permite compreender a quem se destinava esses empreendimentos desde a sua concepção inicial. Ainda segundo Pintaudi e Frúgoli Junior (1992, p. 80):

O sistema de segurança, sem qualquer alarde, tem por tarefa barrar a entrada de mendigos, pedintes, menores de rua etc. Sua ação não se resume aos marginalizados sociais: tem também ordem de retirar da circulação interna aqueles que se desviam do padrão de um frequentador habitual. São também alvo da ação dos seguranças os "punks" - ainda que o indivíduo de camada social mais abastada adote o visual punk apenas como um estilo - e os vanguardistas da moda, com roupas rasgadas ou acessórios exóticos. Os dois tipos são tão indesejáveis quanto os consumidores malvestidos de camadas populares.

O centro destas citações é um convite para refletir sobre o papel excludente destes empreendimentos. Porém, para além destas reflexões, é necessário analisar sob outra ótica, a da centralidade que esses empreendimentos produzem no espaço

Estudos Geográficos, Rio Claro, 16(2): 87-105, jul./dez. $2018 \quad$ (ISSN 1678-698X) http://www.periodicos.rc.biblioteca.unesp.br/index.php/estgeo 
urbano. Os Shoppings Centers tomaram para si o poder de criação de uma centralidade indiscutível, fazendo com que as cidades precisassem construir sua malha urbana considerando as condições de acesso a tais locais, pois tais empreendimentos requerem a circulação de um grande número de pessoas e precisam de grandes terrenos e de vias de acesso fácil. Analisa-se aqui também sobre como o Shopping Center tornou-se um simulacro da cidade. A própria cidade tem estes empreendimentos como modelos. As ruas se "shoppinizam" e o lazer neste espaço é ainda mais contraditório. Este lugar de uso público tem o lazer como ferramenta ao consumo, de maneira tal que as pessoas induzidas por ele consomem, algumas freneticamente. Segundo Hastreiter, Marchetti e Prado (1999, p. 12) "além de transformarem o espaço urbano e influenciarem nos meios de acesso e transporte, são também ambientes simbólicos, integrantes da sociedade e dos padrões que regem o consumo".

A relação de valor contida nas mercadorias por si só é contraditória e dentro das ciências humanas a contradição basilar da reprodução social encontra-se na luta de classes, luta esta que é causada pelo próprio sistema capitalista. As classes, segregadas pelo movimento de reprodução do capitalismo, buscam opções de lazer, afinal esta é uma das necessidades humanas que supõe o trabalho, mas não encontram o lazer com variedade de possibilidades e amplo acesso, e acabam sendo conduzidas ao espaço da mercadoria, e não do lazer propriamente dito.

Neste sentido, a contradição não se destaca pelo fato de o lazer ser praticado no Shopping Center, mas sim pelo seu caráter excludente. A contradição principal está na prática do lazer no espaço planejado e concebido para o consumo e que tem no lazer apenas um atrativo para o ato do consumo se realize. Devido a restrição cada vez maior dos espaços públicos para a prática do lazer, para aqueles que tomam o espaço dos Shoppings Centers como espaço de lazer, metaforicamente, podemos afirmar que o lazer é como o queijo em uma ratoeira, $\mathrm{Ou}$ seja, atrai indivíduos que por vezes visitam aquele espaço apenas com o intuito de circular, ver vitrines, ir ao cinema, desfrutar da praça de alimentação, mas que ao desfrutarem deste lazer acabam realizando o consumo de mercadorias. Fato este que é confirmado por Wypych (2010, p. 142):

Em alguns lugares o signo dominante é o lazer. Noutros o comércio. A área onde se encontram as lanchonetes, a praça de alimentação, é o espaço ritual mais importante, pois ele é marcado pela convergência de pessoas de idades, sexos e ocupações diferentes.

Estes indivíduos acabam iludidos com as mercadorias e seus respectivos signos, sendo laçados pela tentação do consumo e pelas facilidades oferecidas por promoções e parcelamentos, acabando assim, por vezes, fadados a dívidas intermináveis.

O Shopping Center é segregador e, portanto, tomá-lo como espaço de lazer faz com que se torne um lazer destinado a determinados grupos sociais. Concordando com Pintaudi (1992, p.43) quando escreveu sobre as condições de surgimento e estratégias de localização destes empreendimentos, a autora afirma que as "pessoas se identificam de alguma maneira e, portanto, são espaços que segregam, principalmente, em países como o nosso, contribuindo para fragilizar as relações sociais".

Portanto, sendo o Shopping Center um espaço de uso público não deveria ele ser segregador. O Estado enquanto provedor das necessidades de sua Estudos Geográficos, Rio $\quad$ Claro, $\quad 16(2)$ : $\quad 87-105, \quad$ jul./dez. $2018 \quad$ (ISSN $\quad$ 1678-698X) http://www.periodicos.rc.biblioteca.unesp.br/index.php/estgeo 
população tem nestes empreendimentos uma fuga de responsabilidades de prover espaços de socialização e lazer para os indivíduos, provendo inclusive linhas de financiamentos com volumosas quantias do erário a partir do BNDES.

Padilha (2006, p.38) afirma que:

A cidade gera uma série de desajustes, de desigualdades e de contradições, mas também possibilita a criação de espaços considerados 'alternativos', como o próprio Shopping Center. Entretanto, como tudo o que é alternativo, o acesso real ao shopping Center restringe-se a uma pequena parte da população.

Analisando as palavras da autora, as contradições realizam-se dentro de um movimento que permite refletir sobre como a população tomou "posse" (por um tempo determinado, limitado) daquilo que havia tomado no espaço público, afinal, se o shopping é o simulacro da cidade, da praça, das ruas, as pessoas ocupam aquilo que na realidade deveria estar nas ruas da cidade, pois se constrói no shopping uma espécie de cidade fictícia ou, segundo Padilha (2008, p. 106), "artificial, que pretende substituir a cidade real e seus problemas".

O fato do Shopping Center ter assumido a função de espaço de lazer no urbano é algo inegável, porém é preciso entender que o Shopping Center não é um espaço público, mas sim um espaço privado aberto ao público. Isso implica em regras de uso e apropriação que, muitas vezes são excludentes. Como a intenção última do Shopping Center é que o consumo se realize, qualquer prática que possa prejudicar essa lógica ou mesmo afastar pessoas que tenham essa intenção, será proibida, ou seja, há um comportamento esperado e padronizado para os frequentadores. É comum que ocorra, por exemplo, a proibição da entrada de um grupo de pessoas, principalmente se esse grupo for formado por jovens ou adolescentes. Essa prática ganhou força principalmente depois do acontecimento dos "rolezinhos", no fim de 2013, quando alguns Shoppings Centers, principalmente de São Paulo, foram tomados por jovens, em sua maioria de classes baixas, que através das redes sociais marcavam grandes encontros. Essa prática gerou medo por parte dos lojistas, que fechavam as portas, e também de outros frequentadores que não estavam ali para participar do "rolezinho". Rapidamente a administração dos Shoppings Centers começou a proibir a entrada de grupos numerosos de adolescentes, reforçando a segurança aos fins de semana, monitorando as redes sociais para saber quando ocorreriam novos encontros e até mesmo recorrendo à justiça para proibir a entrada de adolescentes desacompanhados de pais ou responsáveis. Essas medidas só ajudam a evidenciar o caráter excludente dos Shoppings Centers e a sua insuficiência em atender toda uma população como opção de lazer.

A partir dos "rolezinhos", a contradição do lazer e do consumo no espaço dos Shoppings Centers se reforça como uma manifestação da segregação e que permite refletir que a disponibilidade do consumo neste espaço não elimina o seu processo de exclusão. Segundo Teixeira, Nascimento e Barros (2014, p. 2) "os "rolezinhos" "foram a manifestação mais explícita de resistência à segregação representada no espaço dos Shoppings Centers". Estes autores analisam esta manifestação social de jovens urbanos sob duas óticas: a da relação entre passeios e o consumo e os passeios e a dimensão política. Segundo levantamentos sobre a relação entre os passeios e o consumo, vemos que a compreensão desse fenômeno é ainda um tanto complexa, segundo Teixeira, Nascimento e Barros (2014, p. 9):

Estudos Geográficos, Rio Claro, 16(2): 87-105, jul./dez. $2018 \quad$ (ISSN 1678 -698X) http://www.periodicos.rc.biblioteca.unesp.br/index.php/estgeo 
Consideramos que a dimensão do consumo está intrinsecamente relacionada aos fenômenos dos roles. No entanto, não sabemos ainda se esse é o aspecto central para a compreensão do fenômeno, que não deve ser pensado de maneira isolada para justificar os roles ou para justificar o porquê agora os jovens se aventuram "em bando" nos espaços dos shoppings. Como se, em um "click", pelo recente aumento do poder de compra de determinados grupos sociais, tivessem resolvido ir então aos shopping centers. [...] Além disso, o outro risco é pensar que somente agora esses jovens consomem especialmente marcas simbolicamente valorizadas, como se apenas agora, por meio de evidências como o crescimento do chamado funk ostentação, eles tivessem se aberto para o consumo. Nesse sentido, ao pontuar a relação entre o role e o consumo, ressaltamos a importância de pensar esse aspecto de uma maneira mais profunda e também mais histórica.

É importante destacar que carregar os signos através das marcas não é algo atualmente restrito as classes sociais mais elevadas e mais favorecidas pelo capital, os grupos da periferia hoje também carregam estes signos, ainda que em produtos falsificados. A periferia das metrópoles hoje também expressa seu poder de consumo, mas, além disso, imita hábitos das classes de renda superiores através da ostentação dos signos que parecem querer mostrar que também fazem parte da sociedade burguesa objetivada pela publicidade das marcas. Pelo consumo das cópias, das falsificações e das imitações, a periferia também tem acesso aos bens de consumo que antes eram privados somente as classes mais abastadas. A mercadoria sai do plano da necessidade, perdendo sua função primária e assume 0 lugar de uma ideologia. Os jovens são alvos desse consumismo e a união entre a oferta de lazer e as publicidades que mostram que os indivíduos são bem sucedidos ao estarem e consumirem nestes espaços faz com que estes sujeitos movimentem 0 mercado. Segundo Sousa e Oliveira (2012, p. 2-3):

Em uma sociedade onde a ostentação do consumo é valorizada, a juventude se torna alvo, pois são os mesmos que como sujeitos da história possuem um poder de articulação e de massificação de culturas, tendências e costumes, conseguindo assim através de tribos e grupos movimentar o mercado, que por sua vez se renova para acompanhar as mudanças dessas juventudes. Contudo vivemos um momento de juvenilização da sociedade, onde o se tornar jovem é ter direito de consumir o que esse mercado oferta.

É desta forma que o consumo gera necessidades desnecessárias e que dentro da sociedade capitalista é o consumo que gera exclusão, e a aceitação pelos grupos só é realizada pela posse e uso das mercadorias. Os Shoppings Centers são entendidos como espaços produzidos para garantir a realização da produção, onde a partir dele objetiva-se garantir uma venda em larga escala que foi intensificada pela divisão do trabalho, o que também permitiu uma produção em larga escala, sendo, portanto, resultado da expansão da produção em massa, que criou o consumo de massa e que utiliza de meios "violentos" para garantir a efetivação deste objetivo.

Estudos Geográficos, $\quad$ Rio $\quad$ Claro, $\quad 16(2): \quad 87-105, \quad$ jul./dez. $2018 \quad$ (ISSN $1678-698 X)$ http://www.periodicos.rc.biblioteca.unesp.br/index.php/estgeo 
Para concluir, é interessante destacar um pensamento de Pintaudi (2008, p.126) sobre o consumo do espaço e a centralidade dos Shoppings Centers nas cidades brasileiras.

O espaço, como mercadoria, também vai ser consumido enquanto signo. Hoje, o lugar da compra, tal como a mercadoria a ser comprada, deve ser diferenciado, deve ter uma marca de distinção de outros que contém mercadorias que não seriam distinguidas e valorizadas se assim não fosse. O lugar como signo se torna abstrato, é consumido como tal, um espaço de consumo que se repete pelas formas que já emergiram. [...] o que é arcaico pode ser diferente num primeiro momento, mas na repetição torna-se indistinto. O fato é que o espaço precisa ser considerado também na perspectiva de consumo do espaço - uma mercadoria que envolve outra, valorizando-a e conferindo distinção àqueles que 0 frequentam.

Tal afirmação nos permite refletir a respeito da crise dos Shoppings Centers em Sorocaba, após 2013. Entre os anos de 2012 e 2015, Sorocaba passou de três Shoppings Centers para oito, ou seja, o número de empreendimentos cresceu pouco mais de $260 \%$ enquanto que, segundo o IBGE (2017), nesse mesmo período o número de habitantes da cidade cresceu pouco mais de $8 \%$. Dentre os Shoppings Centers existentes no município o único que possui uma "marca de distinção" como a autora afirma é o Shopping Iguatemi Esplanada, e é o único que mantém desde sempre seu movimento constante. Desde o seu surgimento, o Esplanada já era uma marca de distinção para a região e quando seu espaço começou a entrar no "comum" do sorocabano ele tornou-se Iguatemi mudando sua forma, trazendo novas empresas, novas marcas, grifes, franquias que ainda não haviam no município. Este empreendimento executou o que Pintaudi (2008, p.126) afirma, "uma forma comercial, para durar, tem de ter capacidade de resistência, precisa ter um sentido, criar raízes, mas para isso ela tem que ser atualizada". E para, além disso, a autora cita que "o que é arcaico pode ser diferente num primeiro momento, mas na repetição torna-se indistinto", ou seja, a forma como os Shoppings Centers em Sorocaba tem sido apresentadas não tem nada de "novo" ela tem se mostrado arcaica. Por meio das observações realizadas em lócus foi possível perceber que nos seus primeiros meses esses empreendimentos que não apresentavam distinção foram bem visitados e frequentados, porém agora só restam funcionários, alguns poucos clientes e lojas abertas até a finalização do contrato firmado. Em maio de 2015, os Shoppings Centers sorocabanos foram notícia no jornal americano The Wall Street Journal (2015), que chamou os empreendimentos de Shoppings fantasmas, referindo-se ao baixo movimento observado nos locais. Um mês depois o jornal brasileiro O Estado de São Paulo (2015) também retratou, no seu caderno Economia e Negócios, o problema dos Shoppings sorocabanos, desta vez com a manchete "Após boom, Sorocaba vê shoppings às moscas". A reflexão que aqui se faz é a de que tais empreendimentos se consolidem e mantenham seus frequentadores caso não possuam renome para ser levado como um signo. É necessário que haja em sua estrutura, arquitetura ou alguma forma inovadora e como os Shoppings em Sorocaba não carregam seus nomes e nem possuem estruturas inovadoras estão hoje em plena decadência.

Estudos Geográficos, $\quad$ Rio $\quad$ Claro, $\quad 16(2): \quad 87-105, \quad$ jul./dez. $2018 \quad$ (ISSN 1678 -698X) http://www.periodicos.rc.biblioteca.unesp.br/index.php/estgeo 


\section{CONSIDERAÇÕES FINAIS}

O Shopping Center é uma estrutura que já faz parte do urbano das médias e grandes cidades, exercendo e oferecendo várias funções e serviços sendo que dentre esses o lazer vem ganhando destaque. Essa é uma das funções que já faz parte do Shopping Center desde o principio, porém apresenta limitações e problemas quando é vista como a principal forma de lazer oferecida no espaço urbano. Na dinâmica da atual sociedade onde os espaços públicos estão sendo relegados pela sociedade e até mesmo pelo poder público o Shopping Center ganha força como opção de lazer. Porém é um espaço que, embora ofereça a possibilidade do encontro e do convívio social, tem como função ser uma forma de comércio, ou seja, é um espaço privado que tem como seu objetivo principal a realização do consumo de mercadorias, o que implica na existência de uma série de regras e padrões de comportamentos em seu interior, alguns desses sendo excludentes.

O urbano é o local da interação da sociedade, das forças capitalistas e do poder público e é dentro dessa lógica que ocorre a criação e recriação dos espaços. Porém, é preciso que haja um equilíbrio entre essas esferas de poder inclusive no âmbito do lazer, para que exista a possibilidade da população recorrer ao lazer em locais onde a centralidade não esteja na mercadoria, como é o caso dos Shoppings Centers. É preciso que, como diz Lefebvre (1991), exista o direito a cidade e aos espaços públicos onde a vida cotidiana aconteça sem imposições, regras de comportamento que proíbam, por exemplo, o encontro e a reunião de grupos.

\section{REFERÊNCIAS}

ARENDT, H. A Condição Humana. 10 ed. Rio de Janeiro: Ed. Forense Universitária, 2000. 352p.

BAUDRILLARD, J. Para uma Crítica da Economia Política do Signo. São Paulo: Martins Fontes Editora, 1972. 278p.

A Sociedade de Consumo. Rio de Janeiro: Edições 70, 1991. 213p.

Função-signo e lógica de classe. In: A economia política dos Signos. São Paulo: Martins Fontes, 1996. pp. 9-49.

BAUMAN, Z. Vida para consumo: a transformação das pessoas em mercadoria. Rio de Janeiro: Zahar, 2008. 199 p.

CARLOS, A. F. (Org.). Novos Caminhos da Geografia. 6. ed. São Paulo: Contexto, 2013. 204 p.

CHIAVENATO, Julio José. Ética Globalizada \& Sociedade de Consumo. 2. ed. reform. - São Paulo: Moderna, 2004.

DICKERSON, Marla; JELMAYER Rogerio. "Ghost Malls" haunt Brazil. The Wall Street Journal. New York. 5 Mai. 2015. Disponível em:

Estudos Geográficos, $\quad$ Rio $\quad$ Claro, $\quad 16(2): \quad 87-105, \quad$ jul./dez. $2018 \quad$ (ISSN 1678 -698X) http://www.periodicos.rc.biblioteca.unesp.br/index.php/estgeo 
<https://www.wsj.com/articles/ghost-malls-haunt-brazil-1430818675>. Acesso em: Nov. 2017.

DUMAZEDIER, Joffre. Sociologia empírica do lazer. Tradução Silvia Mazza e J. Guinsburg - São Paulo: Perspectiva: SESC 1999 - (Debates; 164 p.).

GRANOU, André. Capitalismo e modo de vida: O reino da mercadoria. Califórnia: Afrontamento, 1975. 101.

HARVEY, D. O novo imperialismo. 6. ed. São Paulo: Edições Loyola, 2012. 201 p.

HASTREITER, Silvana, MARCHETTI, Renato e PRADO, Paulo. Tipologia de consumidores baseada nas razões e motivações de frequência em Shopping Centers. In: ENCONTRO DA ASSOCIAÇÃO NACIONAL DOS PROGRAMAS DE PÓS-GRADUAÇÃO EM ADMINISTRAÇÃO. 23. , 1998, Foz do Iguaçu. Anais. Foz do Iguaçu: ANPAD, set. 1999.

IBGE - Instituto Brasileiro de Geografia e Estatística. Cidades@. Sorocaba. Disponível em: <http://cod.ibge.gov.br/234Q2> Acesso em: Nov. 2017.

IBOPE Inteligência. Geonotícias Shopping Centers. 2. ed. Primeiro semestre, $2012 . \quad$ Disponível em: http://www.ibope.com.br/pt$\mathrm{br} /$ solucoes/geonegocios/shopping/Boletim\%20Informativo\%20de\%20Shopping\%20 Center/Boletim\%20Geoneg\%C3\%B3cios.pdf>Acesso em: Jun. 2015.

IBOPE INTELIGÊNCIA. Geonotícias Shopping Centers. 4. ed. Segundo semestre, 2013. Disponível em: < http://www.ibope.com.br/ptbr/solucoes/geonegocios/shopping/Documents/5759\%20_boletim_geonoticias_0411 _FINAL.pdf>. Acesso em: Jun. 2015.

IBOPE INTELIGÊNCIA. Geonotícias Shopping Centers. 5 ed. Primeiro semestre, 2014. Disponível em: < http://www.ibope.com.br/pt-br/conhecimento/BoletimInformativo-de-Shopping/Documents/Boletim_Geonoticias_n\%C2\%BA\%205.pdf> Acesso em: Jun. 2015.

KOHAN, Néstor. Dicionário Básico de categorias marxistas. Extraído e adaptado da obra "Marxismo para iniciantes". Ed. Era Naciente, 2005.

LEFÈBVRE, H. O Direito a Cidade. São Paulo: Ed. Moraes, 1991. 145p. A vida cotidiana no mundo moderno. São Paulo: Ática, 1991.

MARX, K. Introdução à crítica da economia política. São Paulo: Abril, Col. Os $\begin{array}{lllll}\text { pensadores, } & \text { vol. } & 35, & 1974, & \text { pp. }\end{array}$

O Capital: crítica da economia política. Livro I. 32 ed. Rio de Janeiro: Civilização Brasileira, 2014. 571 p.

Estudos Geográficos, $\quad$ Rio $\quad$ Claro, $\quad 16(2): \quad 87-105, \quad$ jul./dez. $2018 \quad$ (ISSN $\quad 1678-698 X)$ http://www.periodicos.rc.biblioteca.unesp.br/index.php/estgeo 
PADILHA, Valquíria. Desafios da crítica imanente do lazer e do consumo a partir do shopping Center. ArtCultura, Uberlândia, v. 10, n. 17, p. 103-119, jul./dez. 2008.

PADOVANI, E. G. R.; A cidade: o espaço, o tempo e o lazer. In: Lucia Helena de Oliveira Gerardi. (Org.). Ambientes: estudos de geografia. Rio Claro: AGETEO, 2003, v. 01, p. 171-184.

PINTAUDI, S. M.; FRUGOLI, Jr. H. Shopping Centers: Espaço, cultura e modernidade nas cidades brasileiras. São Paulo: EDUNESP, 1992. 129 p.

A cidade e as formas do comércio. In: CARLOS, Ana Fani Alessandri (Org.). Novos caminhos da Geografia. São Paulo: Contexto, 2005. Cap. 6, pp. 143-160.

. O consumo do espaço de consumo. In: OLIVEIRA, Márcio Piñon de; COELHO, Maria Célia Nunes; CORRÊA, Aureanice de Mello (Org.). O Brasil, a América Latina e o Mundo: Espacialidades Contemporâneas (II). Rio de Janeiro: Lamparina: Faperj, Anpege 2008. Cap. 3. pp. 121-127.

SALGUEIRO, Teresa Barata. "Globalização e implosão do território", Anales de Geografía de la Universidad Complutense. Madrid, №. 15: 87-98. 1995.

SILVA, C. H. C. A hotelaria e o comércio de luxo nas metrópoles de São Paulo e Buenos Aires. Jundiaí: Paco Editorial, 2014. 220 p.

O tempo e o espaço do comércio 24 horas na metrópole paulista. Rio Claro: UNESP, 2003. Dissertação (mestrado em geografia), IGCE/UNESP, 2003, 224p.

As necessidades, as mercadorias, as marcas e as lojas: A Geografia do Comércio de Luxo em São Paulo. Anais. XI Simpósio Nacional de Geografia Urbana, UNB/AGB, setembro, 2009.

SOUSA, Kamila Costa de; OLIVEIRA, Jaine de Araújo. Juventudes e consumo: um estudo empírico com jovens da periferia de Fortaleza. UFC. 2012.

TEIXEIRA, Juliana Cristina; NASCIMENTO, Marco César Ribeiro; BARROS, Amon. Os rolezinhos em Shopping Centers: Reflexões sobre o que agregam e em que desafiam os estudos dos Shoppings como espaços de segregação social e urbana. In: Encontro de Estudos Organizacionais da ANPAD, VIII, 2014, Gramado - RS. ENEO. Anais. 2014.p.1-16.

TOMAZELA, José Maria. Após boom, Sorocaba vê shoppings às moscas. $O$ Estado de São Paulo. São Paulo. 8 Jun. 2015. Disponível em: <http://economia.estadao.com.br/noticias/geral,apos-boom--sorocaba-ve-shoppingsas-moscas---imp-, 1701894>.

VARGAS, H. C. Comércio e Cidade: Uma relação de origem. Portal do Estado de São Paulo, São Paulo, 31/8/2000. Disponível em:

Estudos Geográficos, $\quad$ Rio $\quad$ Claro, $\quad 16(2): \quad 87-105, \quad$ jul./dez. $2018 \quad$ (ISSN $1678-698 X)$ http://www.periodicos.rc.biblioteca.unesp.br/index.php/estgeo 
<http://www.usp.br/fau/depprojeto/labcom/produtos/2000_vargas_comerciocidaderel acaorigem.pdf>Acesso em: Jun. 2014.

Comércio e Cidade: Uma relação de Origem. In: Claudia Leonor Oliveira; Karen Worcman. (Org.). Memórias do Comércio Paulista. 1. ed. São Paulo: SESC/Museu da Pessoa, 2013, p. 74-79.

VANCE, P. S.; ANGELO, C. F.; FOUTO, N. M. M. D. Estudo do Comportamento de Compra do Frequentador de Shopping Centers na Cidade de São Paulo. Revista de Administração da UFSM, v. 2, p. 130-146, 2009. Disponível em: <http://cascavel.ufsm.br/revistas/ojs-2.2.2/index.php/reaufsm/article/view/1282> Acesso em: Jun. 2015.

WYPYCH, Patrícia Regina. Shopping Center: Espaço de lazer e socialização para o adolescente. Trabalho apresentado no XXXIII Congresso Brasileiro de Ciências da Comunicação no GP Comunicação e Culturas Urbanas. 2010.

Artigo submetido em: 28/03/2018

Aceito para publicação em: 23/10/2018

Publicado em: 14/12/2018

Estudos Geográficos, $\quad$ Rio $\quad$ Claro, $\quad 16(2): \quad 87-105, \quad$ jul./dez. $2018 \quad$ (ISSN 1678 -698X) 